\title{
A Place in the Country
}

\author{
Craig San Roque
}

Consulting Psychologist, Jungian Analyst

Alice Springs, Australia

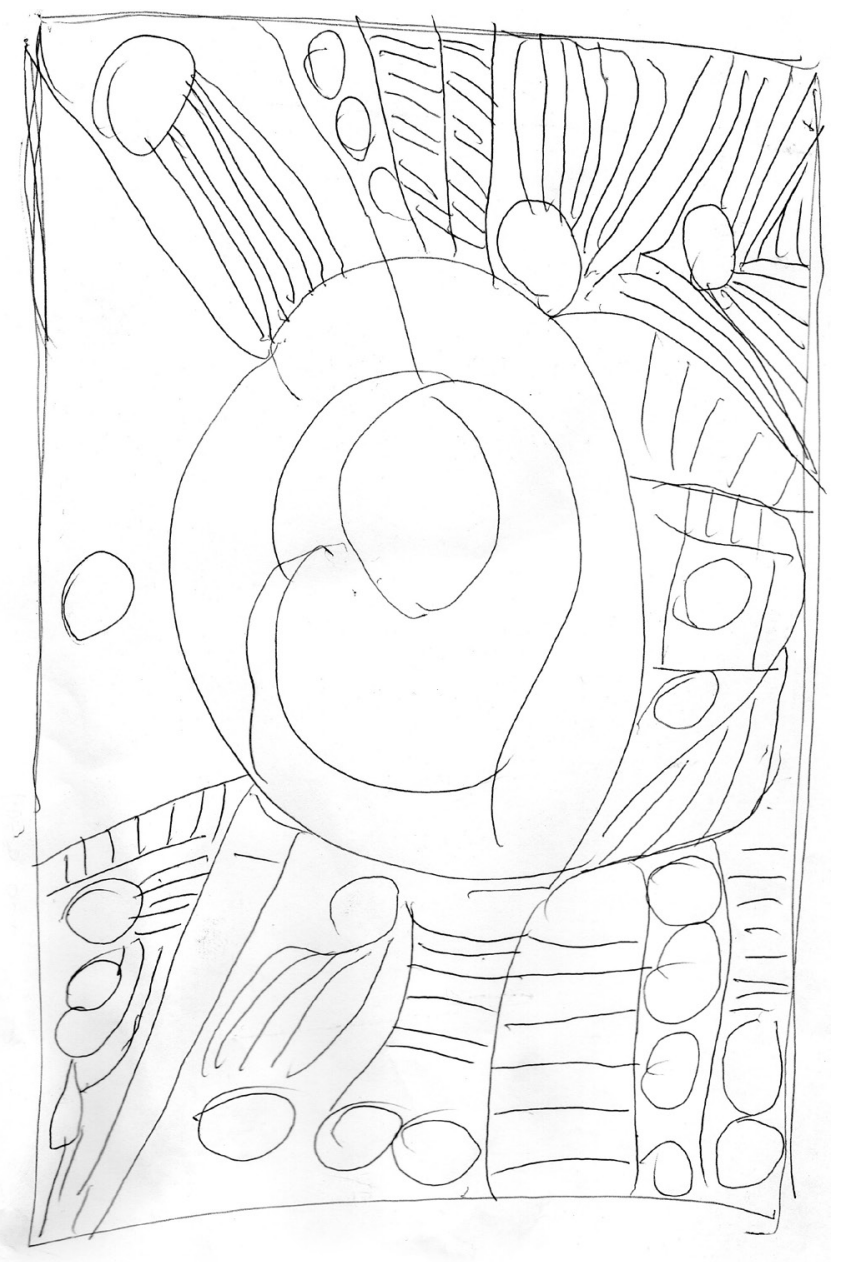

FIGURE 1. A sketch by Marlene Nampijimpa Ross, 2014, drawn while in reverie, thinking about her traditional country.

San Roque. C. (2015). A Place in the Country. Ata: Journal of Psychotherapy Aotearoa New Zealand, 19(1), 11-23. DOI:10.9791/ajpanz.2015.02 (C) New Zealand Association of Psychotherapists Inc. 


\begin{abstract}
This article begins with an outline of an indigenous Australian language concept of "place" then sketches out a schema based on Central Australian graphic patterns and travelling narratives. The schema allows contemplation of various states of being related to place. It philosophically and subjectively considers psychological aspects of location, home, and environment. Notions presented may have pertinence for psychotherapists in practice in multicultural settings in Australia and Aotearoa New Zealand.
\end{abstract}

\title{
Whakarāpopotonga
}

I te tīmatanga ka huri ki te hua i te ariā o te kupu "wāhi” a te iwi taketake, kātahi ka huahuahia he mahere hāngai tonu ki ngā pakiwaitara me ngā momo nuku i te whenua o Te Pū o Ahiteriria. Mā te mahere ka taea te āta whakaaro i ngā whakapapa tauoranga ki tētahi wāhi. Ka āta wānangahia, whakaarohia te wāhanga hinengaro o te wāhi, te kāinga me te taiao. Tērā pea ka hāngai ngā aroro whakaputahia mai ki ngā kaiwhakaora hinengaro e mahi ana i waenga i ngā nōhanga ahurei maha o Ahitereiria me Aotearoa.

Keywords: Warlpiri; ngurra; phenomenology of place

\section{Introduction: Questions on a Sense of Being, a Sense of Place}

$$
\text { Nest — burrow — home - doing — building — dwelling — thinking }
$$

The photo opposite shows a place in the country. It is one image from a series focused on a mound built by termite ants then abandoned. It became the burrow of the endangered native animal known as the bilby, a nocturnal creature. Over months, despite the desolate appearance, this was found to be an active site. The photographic record reveals a sequence of activities by arid land creatures; making a nest, a burrow, a home, doing what they do to survive, eat, procreate, dwelling, and perhaps, in a bilby sort of way, thinking. The picture (Figure 2 ) is one frame in a sequence of photos taken with a movement-activated camera set up to record life around an abandoned termite ant mound with lizard and bilby burrows beneath. The lizard is seen heading into the burrow. In the night sequences the bilby appears, as do camels browsing and a dingo which is hunting bilby.

What creature does not concern itself with a place in which to be? Making a nest, burrow, home - are not such activities fundamental to the sustainment of life of insect, reptile, fish, bird, animal, and human? At what point in our evolutional history as humans did we ever cease to be concerned with a place to be? At what point in the development of psychotherapy did psychotherapists cease to be concerned with the human being's need for a place to be? Is it possible that our profession has become dis-associated from the human need to be in a place, a dwelling, a burrow, a nest, a place, a country? Let us consider such matters. 


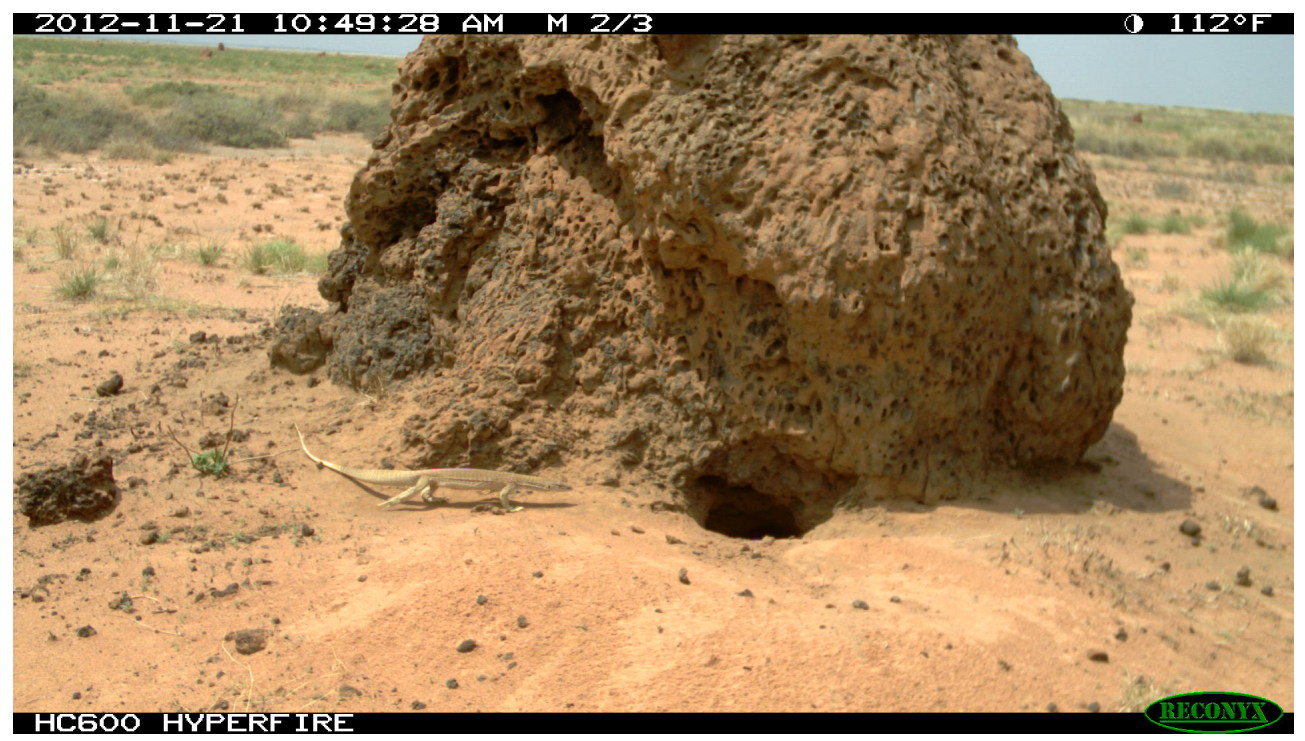

FIGURE 2. A multiple use burrow/ngurra, Tanami Desert, Central Australia. Courtesy of Land Management, Central Land Council

\section{On Warlpiri Places}

In her book Yuendumu Everyday anthropologist Yasmine Musharbash (2008) carefully considered the Warlpiri notion and language of place, space, territory. The Central Australian indigenous Warlpiri are a vigorous group whose custom, law, language, and social organisation were well in place before the coming of the "whiteman" (kardia) into their territory within the regions of the Tanami Desert north-west of Alice Springs. It might be reasonable for us to consider and compare how the Warlpiri think about home/ngurra since the Warlpiri have been in place for many thousands of years. The Warlpiri and their neighbours worked out a way to live successfully enough in this arduous country. They have kept themselves going for a long time. The language and the ontology of "place" or ngurra has probably remained constant and is still deeply held.

For the Warlpiri and their neighbours among the Pintubi, Gurindji, Kaytej, Anmatyerre groups, and others, the significance of place and sites within traditional country is woven indelibly into every aspect of culture, of mentality, and of being. Warlpiri have lived close to the ground and have had time to sort out such things as making and keeping the vitality of the country as sustainment, and keeping the country as a place in mind.

Musharbash's (2008) intimate, philosophically grounded study begs for attention from therapeutic practitioners who are concerned with the wellbeing of peoples and the dynamic of interactions between the environment, physical wellbeing, and mentality, that is to say, how we manage territory and dwell, how we build and destroy, and how we think and feel within the influence of the places where we live and survive. In Yuendumu Everyday, Musharbash invoked Heidegger's philosophical analysis of the sequence building - 
dwelling - thinking, then explained and analysed the Warlpiri term ngurra. She creatively drew on Heidegger's contemplative investigation of the ontology and etymologies of earth, ground, home, place, origin, emergence, and the being of Being, and illuminated it in relation to Warlpiri sense of Being in place and in social order.

In Heidegger's series of - building - dwelling - thinking - the three practices relate in a processual circle. In order to dwell, one has to build; and the way one builds mirrors the way one thinks, which in turn is inspired by the way one dwells.... camp is the Aboriginal English translation of ngurra, which however, holds meanings surpassing those captured by the term camp... Ngurra radiates multiple levels of meaning which afford an incipient understanding of how ngurra is a core concept in Warlpiri language and cosmology. (Mushabash, 2008, p. 33)

Musharbash (2008) went on to describe variations of the Warlpiri concept of ngurra. This description may help us make some discerning differentiations around the various ways in which place is understood in Western concepts and language, and, most particularly, in terms of mental health/psychiatric and therapeutic conceptualisations of the various forms of place, space, boundary, and environ. If a therapist were to examine the language he or she uses in the practice of psychotherapy, at least in relationally attuned, psychodynamically-oriented practices, they might find many phrasings that turn around experiences - in memory, dream, fantasy, and reality - of place and displacement, of home lost and found, of spaces protective and invasive; boundaries and boundary infringements, containments, psychic spaces, being in or out of place, and so forth. The language of psychotherapy recognises such variations of spatial language and the varieties of existential spaces in which we experience our lived existence.

European cultural understandings probably dominate and configure how Australians and New Zealanders think about territory, place, and habitat and probably influence the metaphor bank of conventional psychotherapy. But European sense of place is not the only benchmark. The indigenous understanding of place and country abides and is a source of constant agitation, agony, and contention in our countries. Australia, Aotearoa New Zealand, and the Pacific are now hybridised nations inhabited by peoples whose spatial memories have been formed by histories in diverse global locations.

Immigrations bring memory from diverse places, many devastated. The fate of place haunts the background of people who now make the best and worst of developing our nations, our land, and our cities. Psychotherapists cannot avoid thinking about habitat. I am speaking about habitat as backgrounding mentality - and mentality backgrounding habitat, as in Heidegger's (Steiner, 1978) circular sequence of influence, i.e., dwelling building - thinking - building - dwelling - thinking, that is to say, one thing leads to another. Musharbash (2008) explored this chain in relation to Warlpiri. We might do the same linking and explore Heidegger's chain in relation to our clinical work. Somehow, implicit in this looping formula is the vexing cycle of derangements in mentality derangements in habitat - derangements in mentality. 


\section{On Ngurra}

Musharbash (2008, p. 34) defined ngurra, beginning with the generic notion of shelter and describing eight variations.

1. Generic idea of shelter. Ngurra is something every person and every animal has. It designates the place where one sleeps at night. For people ngurra takes the structure of camp: for animals, ngurra takes the form of whatever physical structure an animal dwells in, e.g. nest, lair, burrow ...

2. Place where one habitually sleeps. Ngurra, in this sense is the term we (women) use to refer to jilimi (the women's camp) when we were all living there.

In a preceding section Musharbash (2008) described the structure and sleeping arrangements of the women's camp, the married people's sleeping arrangements, the single men's, and the single girls'. Each has specific known configurations and boundaries in respect of who sleeps where and beside whom, based on kinship relationships. She continued:

A related term is ngurra-yuntuyuntu denoting a place where many people lived for an extended period of time, a large and long term camp, as for example the original camp sites on the outskirts of settlements ... where Yapa (aboriginal people) lived before houses were built.

3. Home. The emotional bond one can have to one's ngurra becomes more pronounced in the term's added meaning of home, with all the emotional depth that can be attached to it. The phrase ngurra-ngajuku (my home) is generally used in this sense, especially in Warlpiri songs, many of which are about homesickness.

4. Ancestral place. Ngurra also designates the idea of the place with which a person is associated by conception, birth, ancestry, ritual obligation or long term residence; in short, their country ... for example Mawurritjiyi ... is one of old Jakamarra's ngurra, a place with which he has profound emotional associations, a place for which he knew all the songs and dances (i.e. dreaming or jukurrpa), where he had lived in the past for which he was often pining and which he consequently often painted in his dot paintings.

5. Family. The term ngurra-jinta is used to refer to the people living in one camp, typically close kin. It connotes being one family ... Ngurra-jinta presupposes either family connection or long-term cohabitation coupled with emotional affiliation. The Aboriginal English translation of this term is countryman.

6. Ritual division. (In this section Musharbash described in detail the way in which Warlpiri camping areas are oriented with boundaried areas being designated to specific moiety or skin groupings. These groups have specific ritual affiliations with each other.) The terms ngurra-kurlarni-nyarra (camp-southside) and ngurra- 
kurlani-mparra (camp-northside) are used to designate the two patrimoieties into which all Warlpiri are divided ... these groupings are particularly relevant in the ritual context.... During certain rituals these moieties spatially oppose each other ... positioned on the southern and northern sides of the ceremony ground respectively.

7. Time. Ngurra also stands for the period of twenty four hours and is used to designate numbers of days or nights that one would set up camp. For example, when I asked C. about the distance to a settlement up north she answered, "Ngurra jarra" [literally two camps] meaning a three day drive with two overnight stays on the way.

8. Country, the world. Ngurrara means country, fatherland, place, land, home. On one level it is used to refer to one's own country e.g. Mawurritjiyi ... or the Tanami Desert, to the entire Warlpiri lands. However ngurrara does not only denote the expanse of the physical space but everything within it; the people, the animals, the plants, as well as the ancestral beings and spiritual powers contained within the land, the moving clouds, the winds, the stars, the passing of time and so forth... As this inventory makes abundantly clear, 'ngurra' as a term, encapsulates a great number of meanings, beginning with the most generic idea of shelter to the incorporation of the Warlpiri cosmos into a single term. (Musharbash, 2008, pp. 34-35)

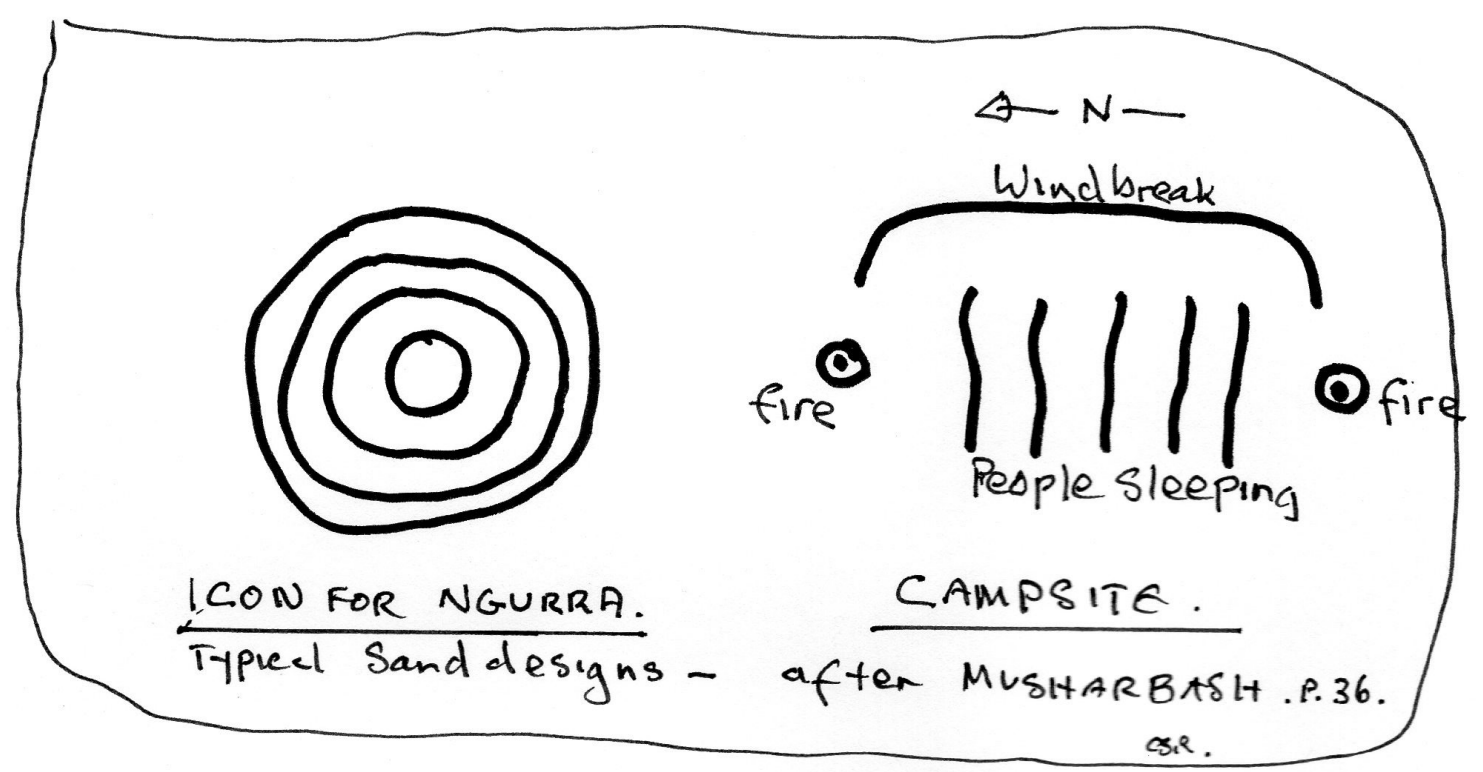

FIGURE 3. Icons of ngurra, place, campsite, as typically seen in sand designs and paintings. 


\section{A Schema of Sorts}

In this section I set out a collection of concepts or dynamic ideas, condensed into a schematic design influenced by Aboriginal pictorial narrative form. As a community psychologist working in indigenous settings I have, with Aboriginal co-workers including Warlpiri senior man, Andrew Spencer Japaljarri, collaboratively developed a distinct style of visual graphic communication and discussion on vital and difficult psychological issues using a synthesis of bicultural narrative forms. This has also been developed as a way of engaged thinking in seminars with therapists. In the Warlpiri symposium-style the design below (Figure 4) would be sketched out on the ground or on a large canvas, perhaps three metres long, around which we might sit, becoming engaged hands-on, developing the symposium in an embodied responsive manner. I find this method emotionally satisfying and more conducive to thinking than other styles such as slide presentations that tend to dissociate personal interactive engagement. While recognising that such media are useful for organised instruction and for conveying ideas, they may contain a fatally dissociative flaw, favouring intellectualisation over thinking and preferencing personal display over learning through embodiment of shared experience in one place.

The mud-map or sand drawing overleaf is moving towards a schema on place and psyche as interactive influences. It explores a number of concepts such as brain, psyche, country, and destroy, preserve, create, and thinking.

The rest of the article elaborates ideas with reference to these sites, beginning at the top of the picture and proceeding down: 1 . Khora, 2. Brain, etc.

\section{Site One: Ngurra/khora}

The Walpiri term ngurra has allowed us to consider place/location in various ways, including camp and women's sleeping place, as well as locating cultural experience, history, country, the cosmos, and the self, seamlessly combined into the sense of a place in which people are contained in dwelling and being. In ancient Greek the term khora resonates in sound and meaning with ngurra. It is, coincidentally, pronounced, in Greek, I understand, as a kind of guttural ghhora, not unlike the pronunciation of ngurra.

In one of Plato's dialogues, Timaeus (Cornford, 1935/1997), a group of men are discussing the origin, form, and nature of creation and of "man", including disorders and disease.Timaeus gives an interesting picture of how such matters may have been configured in Plato's "Academy" which was a place for discussion located in a grove of trees. One section of Timaeus touched on the philosopher's quest for an explanation about how and from where creation emanated. Before getting into the dynamics of creation, Timaeus suggested that the analysis had to go a step backwards in time. He suggested that a pre-existing original condition must be acknowledged. In old Greek this original condition is referred to as khora. Timaeus suggested that khora must have been in place before creation's impulse became active; khora is a more original and necessary condition. Timaeus' point was not comprehensively taken up by Plato but it has been taken up by Casey (2013) in The Fate of Place which I highly recommend to those concerned with the psychology of place. It is this evocative foundational notion, so like that of Warlpiri ngurra, that I am placing on the canvas.

Khora, as I understand it, designates an original holding environment, a state out of 


\section{A PLACE IN THE COUNTRY}

FIGURE 4. Sketch depicting conceptual sites spatially represented, as on a sand map

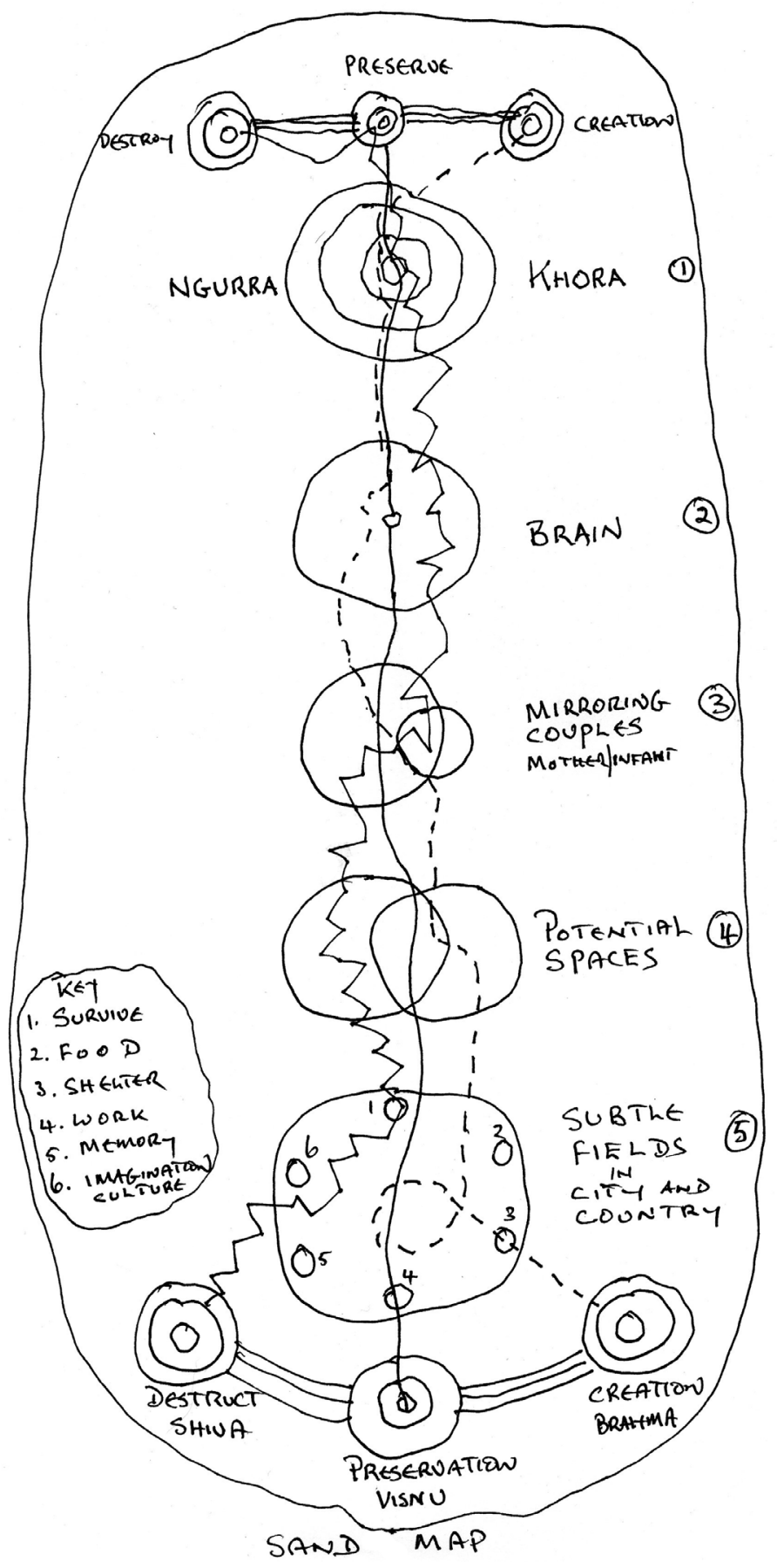


which creation could emerge. Timaeus referred to this state as the "nurse of becoming"; the form and image of a basket is suggested, implying that before acts of creation can take place there must be a holding space, a nursing function (Cornford, 1935/1997, Section 16-20). For myself, this evokes the sense of a Ground of Being, a grounding original condition that holds a steady state from which creation (of any kind) can emerge. This is the site of the "nurse of becoming". In the world in which we live, khora is and becomes manifest as burrow, nest, womb; a place to begin from - that is to say ngurra.

This notion of khora as "nurse of becoming", as original holding ground, makes intuitive sense. The hypothetical existence of khora as the original condition from which life can begin seems logical; it carries a feel of rightness that would resonate with psychotherapists whose rooms and empathic presence cultivate containment and a psychic holding space as a precondition for psychic life to regenerate.

In summary, within this cluster of various language containers (khora/ngurra/home, burrow, place, country, cosmos) are nested strings of concepts and psychological feeling states that encourage us to call to mind emotions, memories, dreams, fantasies, yearnings, nostalgia, attachments, gratitude, and regrets. Similarly, these variations of the human emotional lexicon all arise when we recall ground, nest, burrow, cave, windbreak, wall, building, fireplace, bed, kitchen, dinner cooking, family group gathering, borders lost and found, countries, creatures and humans living in location, space, boundary, home, cosmic original condition, basket, womb, arms nursing, becoming.

\section{Site Two: Brain}

We come now to the neurological system, that interactive, overlapping intersecting, organisational system, the communicative brain. Could we not acknowledge the neurological system as a "nurse of being"? Might brain be thought of as a variation of khora - a preconditional container - a "nurse of becoming" from which thoughts might be born?

Within the brain we find spatial organisation, geographic, locational, territorial orientations - all fundamental to systematic hunting, gathering, cultivating, dwelling, and defence. The neurological system is well-tuned to the significance of place, territory, and the navigation of terrain. Brain is organised so that the activities of man, woman, child, animal, bird, fish, insect, seed, and plant all find a place within which to arrange themselves; alert also to self-protection in case of derangement, alert to continuity, preservation, protection, generativity, and to predation by oneself or from others.

Was there ever a time that the brain did not organise itself around boundary, space, orientation, place, and the use of places? Do either meditation or research on such foundational matters figure significantly in the academy of psychiatric discourses on good mental health and derangement and the therapeutic treatment of human beings?

\section{Site Three: Mirror Neurones, Mother/Child/Father Relations}

Readers will be familiar with psycho-neurological aspects of brain action including research on the activity and function of mirror neurones in child development, mother-child interactions, and psychological nurture. This is the place to acknowledge mammalian 
connectivity and the maternal/paternal presence, and to acknowledge that such interactive processes are foundational concepts in the practice of psychotherapy. Here we consider coupling, the overlapping of beings who create another person and another set of relationships, and create spaces in which these persons can be held, and so on.

This is the place on the map to acknowledge classic processes of generative living conception, pregnancy, birth, the suckling gaze, empathic breath, sheltering arms, tending hand, attentive hold, the empathic moment, receptive attention, mirroring. In terms of developmental processes we are attending here to psychically subtle relational activity between people that is also contained (usually) in a camp, a bed or a house in ngurra. Without that containment and location the human relationship and the developing child or creature could not function healthily.

Is it not at this site that the practice of therapy gathers together concepts of place, space, containment, boundary, direction, territory? Such concepts/acts are gathered into the foundations of practice concentrated within a consulting space functioning as khora. Is it not here that psychotherapists most subtly apply a sense of terrain and track multiple movements within that terrain? A subtle mental field is formed in this overlap of persons; we call this the "therapeutic space".

\section{Site Four: Potential Space}

By now we have shifted attention from neurology through paediatrics to psychodynamic thinking and thus to creatures at play. Let us consider the state of potential space as developed by Winnicott (1971) through his work with children and parents. "Potential space", "the location of cultural experience", and "the place where we live" are terms that developed out of the London schools of psychoanalysis, articulated most clearly by Winnicott, but he too was part of a "tribal group", an interactive psychoanalytic moiety. Here "space" is metaphor of potent connectivity, of playful imagination, of reverie, of conjunctions of self and other, of confrontation of boundaries. Bowlby's $(1979,1988)$ foundational works on attachment dynamics help us with the variations of how people set up their relations whereas Winnicott's foundational works on "potential space" give us a concept of a psychic container wherein distressed relationships might transform, be healed or go on being.

On the basis of this language, it could be assumed that psychotherapists have a strongly developed sense of place. However, acknowledgment of place is most acutely expressed in their understanding of the physical and psychological conditions necessary for therapy to proceed. I do not know how many psychotherapists extend their gratitude for place into an active recognition of the fragility of our physical world (as khora) and how deeply they have thought about, for instance, the trauma of displacement and invasion of territories and homelands and the mental effects of loss of habitat. Here, I am referring to both human loss and to the loss experienced by creatures in their ecosystems. Are these not variations of traumatisation - loss, savagery, destruction of families and siblings, ravages of war, derangement of the neurological khora, obliteration of "nurses of becoming"? All these are variations of bad things that happen to people and creatures during the destruction of terrain, country, homeland. 


\section{Site Five: Subtle Field - Woven Texture}

Here, I use "subtle" in the sense of the Latin word subtil which is a weaver's term describing fine or thin texture. And so we come to the fifth circle or site. I introduce an idea of a designated field of interaction between many people in varying states of being. Imagine a clearing in the forest, an open field, a plaza, village square, playground, arena, ceremonial ground, and perhaps a fire where people gather and have gathered for millennia. The operative thing is the gathering rather than the location.

I designate such a field of interaction as "subtle" because here, although bodies may be seen as jostling, merging, talking, arguing, trading, tackling, fighting, taking fright, or engaged in fertile conjunctions, the interactions imply a weaving of feelings, thoughts, excitements, griefs, and imaginations. The accumulated heat of millions of interactions weave a state of being that is in itself a phenomenon. As we enter such places, a city centre perhaps, we sense and feel the subtly woven field of that place, that city. There is an atmosphere. There are sacred sites in Australia that carry such a feel even though no living human dwells there. The place seems to have a life of its own. There are places in the world that communicate directly with a receptive person, and perhaps there are places that facilitate thinking. All these places could be study sites for psychotherapists provided that, in our pursuit of the inner world, we do not dis-associate from the places of the world itself.

I refer to phenomena that we all experience in many ordinary settings but I am also trying to convey the idea that we should construct and protect spaces where people gather and go about their activities of survival, food gathering and exchange, work, play, reflection, nurturing children, and nurturing vitality. Can our built structures be a little more mindful of the needs of the human psyche?

I now move out from this location on the map to gather some thoughts. Around this hypothetical site I place poles in the ground standing for fundamental human activities. For my purposes, I select six significant factors: survival, work, gathering food, play, memory, and imagination. The interaction and interweaving of these activities in interesting and subtle ways seem to be ingredients in the creation and sustainment of vibrant community places. So here, within and around site five, is a representation of an interactive field among people, and between people, core activities, and their specific environments. The environment includes, naturally enough, explicit and implicit companion processes of animal, bird, fish, reptile, insect, plant life and death; all are proactive elements of nature in seasonal time and all are involved in the pragmatic acts of survival. There are dead spaces and living spaces. Alive spaces are where people are able to play and where memory and imagination are alive. We are creatures of place.

\section{Moving Tracks Six: Shiva's Siblings}

Let us consider the dynamic of destruction, preservation, and creation which you will have your own way of conceiving. It is dramatically personified in Hindu cosmology as conjunctions of six masculine and feminine divinities: Brahma/Sarasvati present the creator forces, Shiva/Parvarti epitomise destructive anarchic forces and, thirdly, their sibling consort couple Vishnu/Laksmi take various incarnations epitomising processes of civilising 
preservation and protection of the cosmos and those who dwell therein. One does not have to subscribe to ancient Hindu ontology and religion to recognise the value of this metaphor for forces operating in life and nature.

Let us now inscribe three lines through the sand, marking the (hypothetical) tracks of creation, destruction, and preservation.

Imagine first a trail of destruction; Shiva/Parvarti in a frenzy, occupying men, women, and children at all points of the five sites. Imagine a Shiva element trailing through neuronal systems, deranging, disorganising, and intoxicating. Imagine a group possessed, a band of militants in frenzies of destruction. Imagine an oligarch destroying food stocks, work, country, city, breaking down civilised interaction, memory, and imagination, and finally destroying the prospect of survival. This is the experience of most human groups over millennia, trauma expected and recalled; the cyclic predation. Within this domain, most of us, as individual practitioners, are hopeless and vulnerable.

On a more intimate scale, at sites three and four, for instance, on our map, Shiva archetypally rages in the everyday destruction of relational couples, mother and infant, father and child, destruction of kin and home. In many such forms, ngurra is destroyed, security broken, boundaries crushed. One way or another psychiatry and psychotherapy pick up such pieces.

A second track can be run through the sand showing lines and forces of protection, defence, preservation, conservation, care, and containment. Psychiatry and psychotherapy have a hand in preserving khora, protecting and repairing the brain, encouraging the empathic mirroring of couples and children, protecting and repairing relationships, nurturing "potential space", and reminding people that we are creatures of place and that ngurra/country is a psychological fact and must be protected and sustained.

The third track carries the potencies of creation, generation, regeneration, and creativity. Psychiatry and psychotherapy have a hand in fostering these. We are not practitioners of impotence, we understand the significance of "nursing becoming" and "being". There are insanities in place-making and there is the insane destruction of places that is the mark of militarised psychopathology. When it comes down to it, although some of our profession support militarised pathologies, many of us have a role in the protection and preservation of civilisation, and many of us, in modest ways, take part in the weaving of culture.

\section{Concluding Thoughts}

Among all forms of life we see indications of dwelling - building - thinking. A sense of place, of ngurra, of khora is woven into the human system. Place/ngurra is as fundamental to life as is dreaming, sleeping, eating, and reproduction. And, yes, a sense of place may already be implicit in the practices of psychiatry and psychotherapy but it could be made more explicit. All therapists carry in their methodology an acknowledgment of containment, boundary, and space as integral to the mentality of the human being. However, the people who formed the early vocabulary of psychotherapy; Freud, Jung, the Londoners, and all the others, were first of all a settled people. Now we are an unsettled people, just as the Warlpiri have been unsettled and resettled and maintain a mobility in these disturbing Australian times. Antipodean psychotherapy has to catch up with the 
psychic effects and truths of unsettlement, displacement, mobility, and the psychic response to this unsettled fact. From this point on I do not know where to go.

\section{Acknowledgements}

This article is based on a presentation I gave at a seminar for the Section of Social and Cultural Psychiatry, Royal Australian and New Zealand College of Psychiatrists held in Perth, Western Australia on 15th November 2014, the theme of which was "Sense of being, sense of place: How significantly does the world around us shape our lives? An exploration of culture, communities, cities”. I express deep gratitude to Yasmine Mushabash, the author of Yuendumu Everyday: Contemporary Life in Remote Aboriginal Australia, for her insightful, grounding work, and hope I have represented her text with consideration. I also express my thanks to the workers and board members of the Warlpiri Youth Development Aboriginal Corporation, also known as the Mt Theo Program (see www.mttheo.org).

\section{References}

Bowlby, J. (1979). The making and breaking of affectional bonds. New York, NY: Routledge.

Bowlby, J. (1988). A secure base: Clinical applications of attachment theory. London, UK: Routledge.

Casey, E. (2013). The fate of place. Oakland, CA: University of California Press.

Cornford, F. M. (1997). Plato's cosmology: The Timaeus of Plato, translated with a running commentary. Indianapolis, IN: Hackett Publishing Company. (Original work published 1935)

Musharbash, Y. (2008). Yuendumu everyday: Contemporary life in remote Aboriginal Australia.

Acton, Australia: Aboriginal Studies Press,

Steiner, G. (1978). Heidegger. London, UK: Fontana Press.

Winnicott, D.W.(1971). Playing and reality. London, UK: Tavistock.

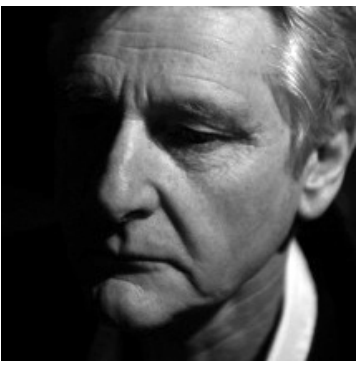

Dr Craig San Roque is a consulting psychologist and Jungian analyst. He trained in London and has long experience in urban-based psychotherapy and remote-area community work. He is practice supervisor for the Central Australian remote psychiatric and primary mental health teams and works with several indigenous-based organisations, including collaborations with traditional healers (ngangkari) working across Central Australia. Craig is currently involved with a project gathering and distilling bicultural mental health practice, language, ontology, and methodologies. Recent publications include Placing Psyche: Exploring Cultural Complexes in Australia (Spring Journal and Books, 2011) which he edited with Amanda Dowd and David Tracey. Contact details: roq@ozemail.com.au . 